\title{
Development of a Capillary Electrophoresis Method for the Separation of Fluoroquinolone Derivatives in Acidic Background Electrolyte
}

\author{
Rusu Aura, Hancu G, Gyéresi Á \\ Department of Pharmaceutical Chemistry, Faculty of Pharmacy, University of Medicine and Pharmacy, Tîrgu Mureș, Romania
}

\begin{abstract}
Introduction: Antibacterial quinolones class comprises a series of synthetic antibacterial agents, following the model of nalidixic acid. Because of their common 6-fluorosubtituent on the quinolone ring, fluroquinolones are the most potent analogues with extended spectrum of activity and great pharmacokinetic properties. The applicability of capillary zone electrophoresis for the separation of fluoroquinolones in acidic background electrolyte has been studied, our aim being the development of a capillary zone electrophoresis method for the simultaneous separation of six fluoroquinolones and also to optimize the analytical conditions. The six studied fluoroquinolones were ciprofloxacin, enoxacin, enrofloxacin, moxifloxacin, ofloxacin and sarafloxacin.

Material and methods: Preliminary, we studied the electrophoretic behavior of six fluoroquinolones in an acidic pH, which highlighted the possibility of developing a separation method in this area of $\mathrm{pH}$. Electrophoretic parameters influencing separation performance were studied and optimized.

Results: A fast and reliable method has been developed, using a background electrolyte containing $100 \mathrm{mM}$ phosphoric acid and the following conditions: applied voltage: $+25 \mathrm{kV}$, temperature: $20^{\circ} \mathrm{C}$, injection pressure $30 \mathrm{mbar}-5 \mathrm{sec}$, UV detection at $280 \mathrm{~nm}$, capillary: $60 \mathrm{~cm}(52 \mathrm{~cm}$ effective length) x $50 \mu \mathrm{m}$, analyte concentration: $167 \mu \mathrm{g} / \mathrm{ml}$. The separation of the studied fluoroquinolones was achieved in less than 8 minutes. Conclusions: Capillary zone electrophoresis using an acidic background electrolyte proved to be an efficient tool in the separation of fluoroquinolones from different generations. Also the proposed methods are particular environment-friendly replacement and improvement of a common high performance liquid chromatography determination with rapid analysis time without using any organic solvents.
\end{abstract}

Keywords: fluoroquinolones, capillary zone electrophoresis, acidic background electrolyte, separation

Received: 11 June 2013 / Accepted: 7 June 2014

\section{Introduction}

Antibacterial quinolones comprise a series of synthetic antibacterial agents, following the model of nalidixic acid, introduced in therapy in 1962 for the treatment of urinary tract infections. These potent analogues with extended spectrum of activity and great pharmacokinetic properties are more suitable for the treatment of systemic infections; are classified as fluoroquinolones (FQs), because of their common 6-fluorosubtituent on the quinolone ring [1-3]. The therapeutic importance of FQs is closely linked with analytical aspects, consequently the elaboration of new methods for their analysis is a permanent necessity, but also taking in consideration structural similarities between compounds a considerable challenge. The most frequently applied methods for the analysis of QNs are the chromatographic ones, especially high performance liquid chromatography (HPLC). Because of its separation efficiency, low amount of sample and reagents consumption, speed of analysis and applications to a wider selection of analytes, capillary electrophoresis (CE) is gaining momentum in the analysis of pharmaceutical substances, being regarded nowadays as an alternative and also a complementary method for the more frequently used HPLC [4]. In the past few

Correspondence to: Aura Rusu

E-mail: aura.rusu@umftgm.ro years CE proved to be an important tool in the analysis of quinolone derivatives, but the large majority of the developed methods describe separation in a basic background electrolyte (BGE) [5-9]. The acid-base properties of these substances have major implications in the mechanism of action and pharmacological properties [10,11]. As zwitterionic molecules, FQs are characterized by protonation equilibria constants. Protonation of specific sites is related with microscopic protonation constants, which offer the $\mathrm{pH}$ dependent concentrations of protonated microspecies. They are responsible for interaction with biological receptors, binding to DNA-gyrase, complexation with metals $[12,13]$. In a previous study we presented the complete macro- and microeqilibrium analysis of six representative FQs and we have determined the protonation centers: the 3 position carboxylate group and piperazine nitrogens $\mathrm{N}-1$ ' and N-4'. Data from this study are very useful, representing a starting point in developing methods of electrophoretic analysis [14]. FQs are amphoteric substances, will be negatively or positively charged depending on the $\mathrm{pH}$ of the environment, offering the possibility of using either an acidic or an alkaline running buffer for their separation. Most published CZE separation methods are based on a basic BGE, while the acidic BGE are less tested [15-17].

The aim of the present study was to develop an alternative CE method for the simultaneous separation of FQs in 
<smiles>O=C(O)c1cn(C2CC2)c2cc(N3CCNCC3)c(F)cc2c1=O</smiles><smiles>CCn1cc(C(=O)O)c(=O)c2cc(F)c(N3CCNCC3)nc21</smiles><smiles>COc1c(N2CC3CCCNC3C2)c(F)cc2c(=O)c(C(=O)O)cn(C3CC3)c12</smiles>

Moxifloxacin<smiles>CC1COc2c(N3CCN(C)CC3)c(F)cc3c(=O)c(C(=O)O)cn1c23</smiles><smiles>CCCCC(C)n1cc(C(=O)O)c(=O)c2cc(F)c(N3CCN(CC)CC3)cc21</smiles><smiles>O=C(O)c1cn(-c2ccc(F)cc2)c2cc(N3CCNCC3)c(F)cc2c1=O</smiles>

Fig. 1. The chemical structures of the studied FQs

acidic BGE conditions and also to optimize the analytical conditions. For this purpose we selected six FQs from various generations of extensive therapeutic human and veterinary use: ciprofloxacin, enoxacin and ofloxacin from second generation, moxifloxacin from fourth generation, enrofloxacin and sarafloxacin, two compounds for veterinary use. These selected molecules exhibit different structural characteristics but in the same time exhibit closely related structures (Figure 1).

\section{Methods}

\section{Materials and apparatus}

The FQs were purchased as follows: ciprofloxacin hydrochloride (CIP), ofloxacin (OFL) from Ranbaxy Laboratories Limited, enoxacin (ENO) from Fluka, enrofloxacin (ENR) from Sigma-Aldrich, moxifloxacin hydrochloride (MOX) from Bayer Schering Pharma AG, and sarafloxacin (SAR) from Orichem International LTD. All substances were of pharmaceutical grade. Other reagents: acetonitrile, phosphoric acid, trisodium phosphate, potassium tetraoxalate, potassium hydrogen phthalate, potassium dihydrogen phosphate, disodium hydrogen phosphate, and borax from Merck, methanol, sodium hydroxide from Lach-Ner. All reagents and solvents were of analytical grade. The deionized water prepared with a Milli Q water purification system (Millipore) was used for throughout the experiments.

All experiments were performed using an Agilent 6100 CE system (Agilent) equipped with diode-array detector, while the results were recorded and processed using Chemstation 7.01 software (Agilent). The experiments were performed using uncoated fused-silica capillaries of 48-70 $\mathrm{cm} \times 50 \mu \mathrm{m}$ internal diameter (effective length $40-62 \mathrm{~cm}$ ) (Agilent).
The $\mathrm{pH}$ was adjusted using a Terminal 740 (Inolab) $\mathrm{pH}-$ meter.

\section{CE Method}

The detection was carried out in UV at $280 \mathrm{~nm}$, taking in consideration the UV absorption maxima of the studied FQs. The individual compounds were identified in the mixture by their UV spectra and migration time. In all measurements hydrodynamic sample injection was used, by injecting the sample at the anodic end of the capillary, with the detector at the cathodic end. The FQs stock solutions were prepared by dissolving the substance in methanol at concentrations of $10 \mathrm{mg} / \mathrm{ml}$, were stored in the refrigerator at $+4^{\circ} \mathrm{C}$, and later diluting it to an appropriate concentration $(1 \mathrm{mg} / \mathrm{ml})$. The solutions were treated in an ultrasonic bath for $10 \mathrm{~min}$ and filtered through a syringe filter of $0.45 \mu \mathrm{m}$ pore size.

Separations were performed using a fused-silica capillary of $60 \mathrm{~cm} \times 50 \mu \mathrm{m}$ I.D. (effective length: $52 \mathrm{~cm}$ ) from Agilent. At the beginning of each day the capillary was conditioned with $0.1 \mathrm{M} \mathrm{NaOH}$ (5 min), deionized water (5 $\mathrm{min})$ and BGE (10 $\mathrm{min})$. The capillary was preconditioned before every run with water (1 min) and BGE $(3 \mathrm{~min})$.

The $\mathrm{pH}$ values were measured with a combined glass electrode (Inolab). The $\mathrm{pH}$ data were based $\mathrm{pH}$ meter readings upon NIST primary standards: $0.05 \mathrm{M}$ potassium tetraoxalate $(\mathrm{pH}=1.68), 0.05 \mathrm{M}$ potassium hydrogen phthalate $(\mathrm{pH}=4.01), 0.025 \mathrm{M}$ potassium dihydrogen phosphate $+0.025 \mathrm{M}$ disodium hydrogen phosphate $(\mathrm{pH}$ = 6.87) and $0.01 \mathrm{M}$ borax $(\mathrm{pH}=9.18)$ [18].

\section{Results}

\section{Preliminary study}

Initial runs were carried out to assess the feasibility of phos- 


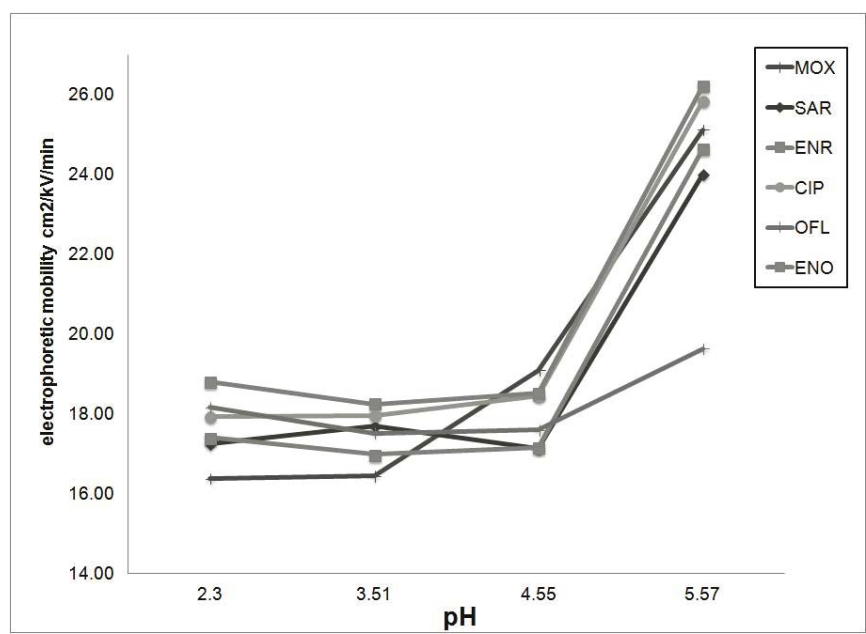

Fig. 2. Electrophoretic mobility versus electrolyte $\mathrm{pH}$ in an acidic environment (separation condition: buffer $25 \mathrm{mM}$ phosphoric acid, capillary: $60 \mathrm{~cm}$ (52 cm effective length) x $50 \mu \mathrm{m}$, applied voltage: $+25 \mathrm{kV}$, temperature: $25^{\circ} \mathrm{C}$, injection pressure $30 \mathrm{mbar}-5 \mathrm{sec}$, analyte concentration: $1 \mathrm{mg} / \mathrm{ml}$ ).

phate buffer as BGE. Phosphate buffer (phosphoric acid) was used for $\mathrm{pH}$ values between 2 and 7, the initial buffers concentration was set at $25 \mathrm{mM}$, in order to modify $\mathrm{pH}$ we added $0.1 \mathrm{M} \mathrm{NaOH}$ solution to the BGE. Using an acidic BGE solution, migration times decreased with the increase of the $\mathrm{pH}$ values and electrophoretic mobilities generally increases with the increase of the $\mathrm{pH}$, as at low $\mathrm{pH}$ values $\mathrm{EOF}$ is very small and affects slightly the migration, without an improvement of the separation resolution (Figure 2).

The migration of each FQ can be reasonably explained by the ionization fraction of the analyte at each $\mathrm{pH}$. At a $\mathrm{pH}$ value of the $\mathrm{BGE}$ around 7 , there were no electrophoretic signals on the electrophoregram, because at this $\mathrm{pH}$ the predominant microspecies of FQs are neutral. These preliminary measurements suggest a better separation of the FQs using an acidic BGE with $\mathrm{pH}$ under 3.5, which is directly linked to protonated microspecies.

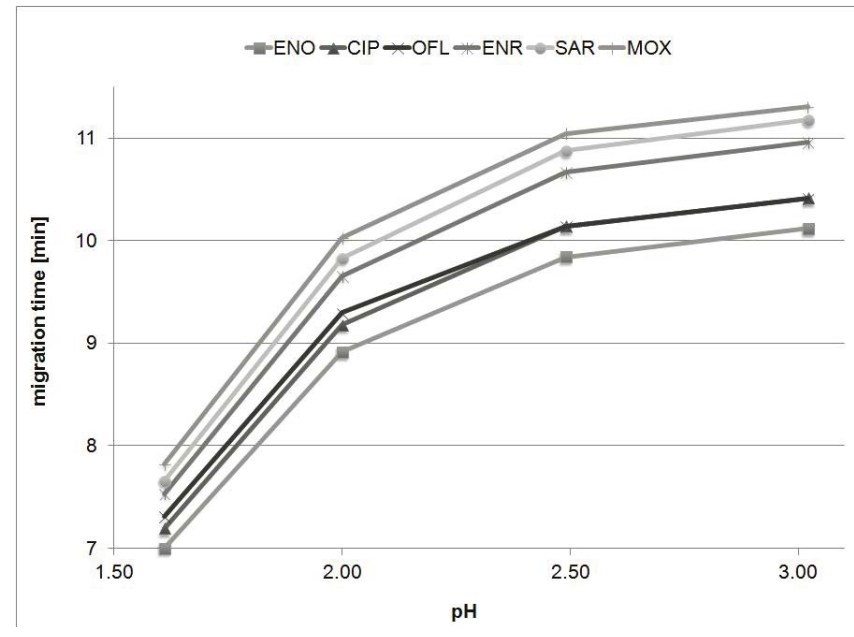

Fig. 4. Variation of the migration times depending on the $\mathrm{pH}$ of BGE. Separation condition: BGE $100 \mathrm{mM}$ phosphoric acid, applied voltage: $+25 \mathrm{kV}$, temperature: $25^{\circ} \mathrm{C}$, injection pressure $30 \mathrm{mbar}-5$ sec.

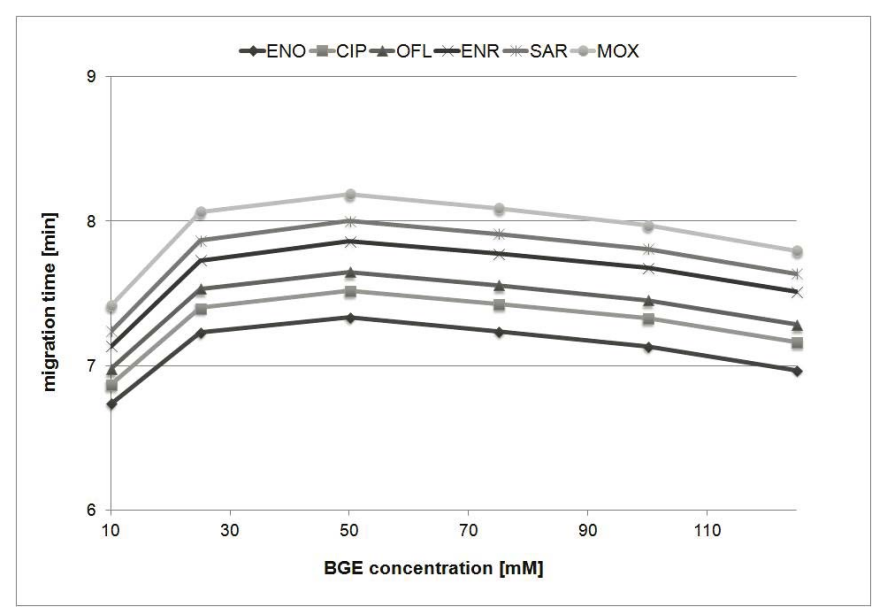

Fig. 3. Variation of the migration times depending on the buffer concentration. Separation condition: buffer 10 - $125 \mathrm{mM}$ phosphoric acid, capillary: $60 \mathrm{~cm}$ (52 cm effective length) $\times 50 \mu \mathrm{m}$, applied voltage: $+25 \mathrm{kV}$, temperature: $25^{\circ} \mathrm{C}$, injection pressure 30 mbar $-5 \mathrm{sec}$.

\section{Optimization of the CE analytical conditions}

Electrophoretic parameters (BGE concentration, applied voltage, temperature, injection pressure and time) influencing separation performance were studied and optimized.

Influence of the concentration of $B G E$. When using an acidic BGE an increase in the electrolyte concentration first increased and then at a concentration above $50 \mathrm{mM}$ decreased the migration times of the analytes, as the effect of electroosmotic flow (EOF) on the separation is low (Figure 3).

Migration times and electrohoretic mobilities are less influenced by an increase of the buffer concentrations when using an acidic BGE. The use of BGE with high concentration is limited by the generation of high currents, which should be avoided, because can generate instability of the electrophoretic system. The optimum buffer concentration was set at $100 \mathrm{mM}$ phosphoric acid.

Influence of $p H$. The migration time is also influenced by the $\mathrm{pH}$ values. These were manipulated by adding triso-

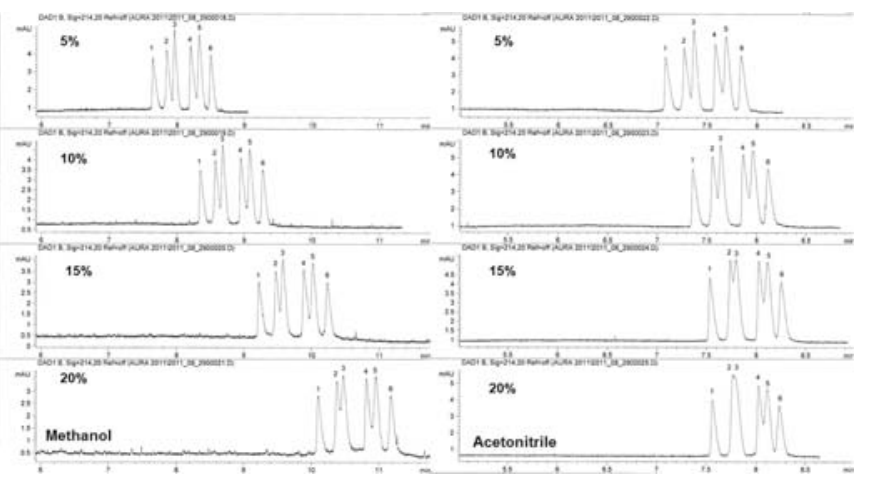

Fig. 5. Comparative electrophoregrams obtained with BGE 100 $\mathrm{mmM}$ phosporic acid and different amounts of additives (methanol and acetonitrile). Migration order: 1. ENO, 2. CIP, 3. OFL, 4. ENR, 5. SAR and 6. MOX. Separation condition: applied voltage: $+25 \mathrm{kV}$, temperature: $25^{\circ} \mathrm{C}$, injection pressure $30 \mathrm{mbar}-5 \mathrm{sec}$. 


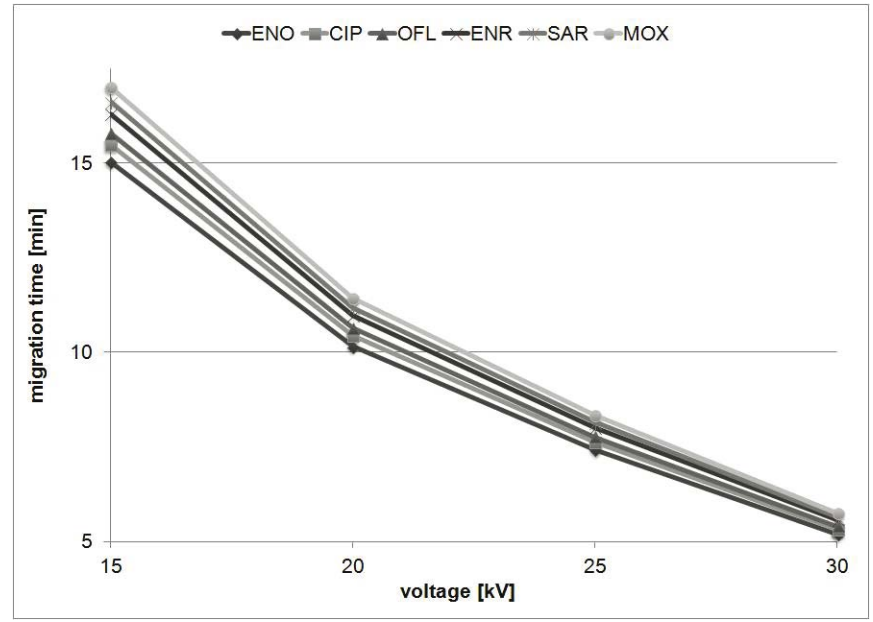

Fig. 6. Variation of the migration times depending on the applied voltage. Separation condition: BGE $100 \mathrm{mM}$ phosphoric acid, temperature: $25^{\circ} \mathrm{C}$, injection pressure $30 \mathrm{mbar}-5 \mathrm{sec}$.

dium phosphate to the BGE solution. Low values of $\mathrm{pH}$ lead to the decreasing the migration time and to a better resolution of separation. At higher values of the $\mathrm{pH}$, the separation resolution was poor and electrophoregram showed only five analytical signals because CIP and OFL had the same migration time (Figure 4). The optimum $\mathrm{pH}$ of $\mathrm{BGE}$ was set at value 1.6 which was the most acidic $\mathrm{pH}$ experimented.

Influence of additives. In order to increase the selectivity of the separation and to obtain a better resolution we used organic solvents (methanol and acetonitrile) as BGE additives. Our aim was to modify the electrophoretic mobilities of the analytes. Increasing the organic solvent concentration in the buffer solutions reduces the EOF, consequently increasing migration time. By comparison, methanol led to a higher increase of migration time than acetonitrile, and also negatively influenced the shape of the baseline of the electrophoregrams (Figure 5).

Influence of applied voltage. The migration times decreased with the increase of the applied voltage, the limiting factor here being the Joule heating (Figure 6). The optimal voltage was set at $+25 \mathrm{kV}$ and determined by performing runs at increasing voltages until the deterioration in the separation resolution was observed. The particular

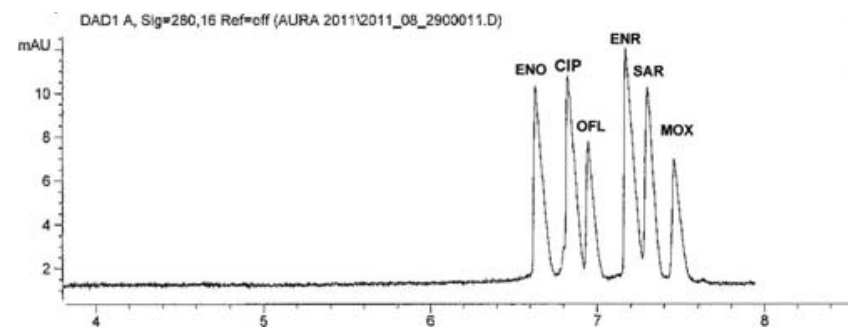

Fig. 8. The separation electrophoregram of a mixture of 6 QNs. Separation conditions: buffer $100 \mathrm{mM}$ phosphoric acid, $\mathrm{pH}-1.6$, applied voltage: $+25 \mathrm{kV}$, temperature: $20^{\circ} \mathrm{C}$, injection pressure 30 mbar $-5 \mathrm{sec}$, UV detection at $280 \mathrm{~nm}$, capillary: $60 \mathrm{~cm}(52 \mathrm{~cm}$ effective length) $\times 50 \mu \mathrm{m}$, analyte concentration: $167 \mu \mathrm{g} / \mathrm{ml}$.

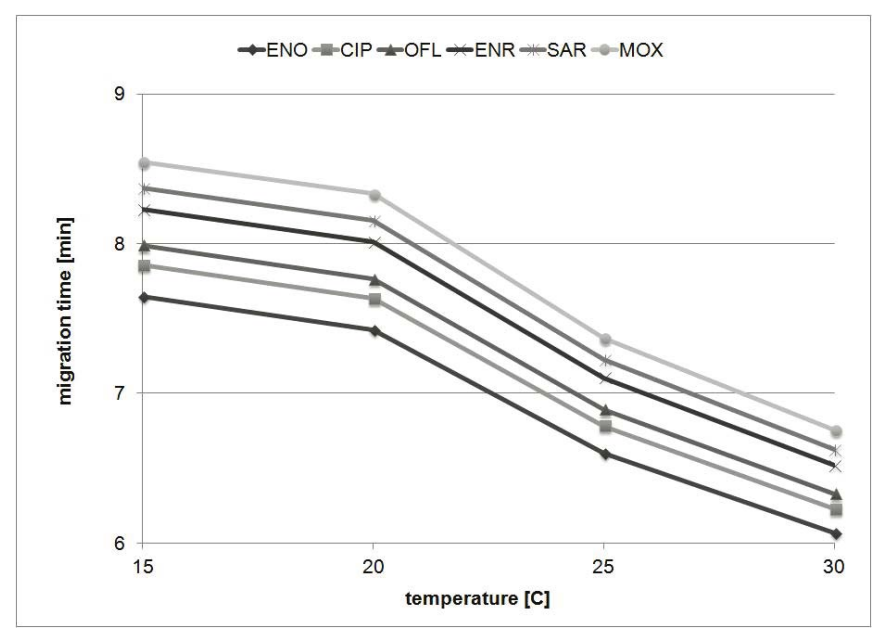

Fig. 7. Variation of the migration times depending on the temperature. Separation condition: BGE $100 \mathrm{mM}$ phosphoric acid, applied voltage: $+25 \mathrm{kV}$, injection pressure $30 \mathrm{mbar}-5 \mathrm{sec}$.

reason we selected this voltage was the migration time for all analytes under 10 minute.

Influence of temperature. Increasing the system temperature led to the decrease of buffer viscosity resulting in the increase of electrophoretic mobility and the decrease of migration times (Figure 7). The studied FQs are stable in the selected temperature interval. The optimal working temperature was set at $20^{\circ} \mathrm{C}$ in order to obtain a better separation resolution and lower values of migration times.

Influence of the injection pressure and time of injection. The injection pressure and time influenced only slightly the migration times of the analytes in terms of decreasing the migration time values. A 30 mbar injection pressure and a 5 seconds injection time were selected in order to avoid peak splitting and band broadening and to obtain the best separation resolution of the analytes.

\section{Separation in acidic BGE}

As it can be seen in the preliminary study, all the analytical signals of the six selected derivatives can be detected in acidic BGE. A BGE $100 \mathrm{mM}$ phosphoric acid at a $\mathrm{pH}$ of 1.6, was selected. Using a $60 \mathrm{~cm}$ long $(52 \mathrm{~cm}$ effective length) capillary, the six FQs could be separated in less than 8 minutes, the migration order being: ENO, CIP, OFL, ENR, SAR and MOX (Figure 8) with suitable separation parameters (Table I).

\section{Discussion}

In order to choose the most efficient BGE solution for the separation an important parameter to be considered are the acid-base properties of the analyte, expressed by the $\mathrm{pKa}$ values. FQs exhibit three $\mathrm{p} K_{\mathrm{a}}$ values corresponding to the 3 -carboxylic group $\left(\mathrm{p} K_{\mathrm{a} 1}\right)$ from the quinoline cycle respectively to the nitrogen $\mathrm{N}-4^{\prime}\left(\mathrm{p} K_{\mathrm{a} 2}\right)$ and $\mathrm{N}-1^{\prime}\left(\mathrm{p} K_{\mathrm{a} 3}\right)$ from the piperazine cycle [14]. Most FQs are hydrophobic compounds and exists as zwitterions (nitrogen atoms - proton donor, carboxylic group - proton acceptor). Usually FQs 
Table I. The electrophoregram parameters of the six FQs separation

\begin{tabular}{|c|c|c|c|c|c|c|c|c|}
\hline Substance & $\operatorname{tm}(\min )$ & Area (mAU*s) & Height (mAU) & Symmetry & Width (min) & Plates & Resolution & Selectivity \\
\hline ENO & 6.65 & 31.42 & 8.81 & 0.21 & 0.05 & 87498 & - & - \\
\hline CIP & 6.82 & 35.51 & 9.42 & 0.30 & 0.05 & 87082 & 2.01 & 1.03 \\
\hline ENR & 7.12 & 40.26 & 10.57 & 0.21 & 0.06 & 84248 & 2.40 & 1.03 \\
\hline SAR & 7.24 & 30.54 & 8.83 & 0.36 & 0.05 & 115213 & 1.34 & 1.02 \\
\hline MOX & 7.38 & 19.12 & 5.56 & 0.32 & 0.05 & 120122 & 1.79 & 1.02 \\
\hline
\end{tabular}

are separated in an alkaline BGE as negatively charged FQs will migrate against EOF, but some can be separated also in an acidic BGE, where the positively charged FQs will move in the same direction with the strongly suppressed EOF. The impact of $\mathrm{pH}$ on such complex zwitterionic derivatives is substantial; as the charge of these compounds is $\mathrm{pH}$ dependent, variations in buffer $\mathrm{pH}$ would change their surface charge densities and consequently electrophoretic mobilities and the selectivity of separation is affected by $\mathrm{pH}$. The six selected compounds have relatively different chemical structures: ENO - a naphthyridine derivative, CIP and ENR - quinoline derivatives (ENR is different by an ethyl moiety in position $\mathrm{N}^{\prime}-4$ of the piperazinic ring), SAR - a difluoride quinoline derivative, MOX also a quinoline derivated which has a 7-bicycle (pirolidino-piperidine) and an 8-methoxy moieties, and OFL - a tricycle derivative (Figure 1). Specific reported values regarding macroconstant and microconstant of protonation equilibria of antibacterial quinolones group are presented in Table II.

All microspecies involved in the protonation echilibria, $\mathrm{HL}^{-}, \mathrm{HL}, \mathrm{HL}^{+}, \mathrm{HL}^{2+}$ are present in the electrophoretic system. At low values of $\mathrm{pH}$ the monoprotonated form predominates for all molecules and also the double protonated microspecies could be found, too [14]. The effective electrophoretic mobility of each individual FQs is composed of two positive microspecies. All molecules of HL effective have no charge and migrate with the EOF. The effective mobility equation $\left(\mu_{\mathrm{ef}}\right)$ from a generalized mobility equation involving multiprotolytic equilibria is shown below:

$\mu_{\mathrm{ef}}=\alpha_{\mathrm{HL}^{2+}}^{2+} \mu_{\mathrm{HL}^{2+}}^{2+} \alpha_{\mathrm{HL}^{+}}^{+} \mu_{\mathrm{HL}^{+}}+\alpha_{\mathrm{HL}^{-}}+\mu_{\mathrm{HL}}^{-}$

$\mu_{\mathrm{ef}}=\left(\left[\mathrm{H}_{3} \mathrm{O}^{+}\right]_{3} \mu_{\mathrm{HL}}^{2+}+K_{\mathrm{a} 1}\left[\mathrm{H}_{3} \mathrm{O}^{+}\right]_{2} \mu_{\mathrm{HL}^{+}}+K_{\mathrm{a} 1} K_{\mathrm{a} 2} K_{\mathrm{a} 3} \mu_{\mathrm{HL}}{ }^{-}\right)$

$/\left(\left[\mathrm{H}_{3} \mathrm{O}^{+}\right]_{3}+K_{\mathrm{a} 1}\left[\mathrm{H}_{3} \mathrm{O}^{+}\right]_{2}+K_{\mathrm{a} 1} K_{\mathrm{a} 2} K_{\mathrm{a} 3}\right)$

where $\mu=$ limiting electrophoretic mobility, $\alpha=$ a particular charged of microspecies of FQs, $K_{\mathrm{a}}=$ dissociation constants $\left(K_{\mathrm{a} 1}, K_{\mathrm{a} 2}\right.$, and $K_{\mathrm{a} 3}$ are dissociation constants of compounds).

We can consider the last two members of the equation (1) with 0 values. Already it is considered that the FQs have much weaker acid character comparative with other aromatic carboxylic acid, explained with the intramolecular H-bond between 3-carboxyl and the 4-carbonyl groups $[20,26]$. Typically, in the case of weak acids the expression for dissociation constant of a weak acid is well known

$-\log K_{\mathrm{a}}=-\log \left[\mathrm{H}_{3} \mathrm{O}^{+}\right]-\log ([\mathrm{A}-] /[\mathrm{HA}])$

equation which can be calculate the $\mathrm{pH}$ :

Table II. The reported protonation constants of studied FQs

\begin{tabular}{|c|c|c|c|c|c|}
\hline Substance & $\log K_{1}$ & $\log K_{2}$ & $\log K_{3}$ & Method & References \\
\hline \multirow[t]{3}{*}{ Ciprofloxacin } & 8.89 & 5.90 & & Potentiometry / Fluorimetry & [19] \\
\hline & 8.95 & 6.35 & & CE & [15] \\
\hline & 8.61 & 6.30 & -0.21 & 1H-NMR titration & [14] \\
\hline \multirow[t]{2}{*}{ Enoxacin } & 8.30 & 5.75 & 5.15 & CE & [15] \\
\hline & 7.53 & & & UV spectrophotometry & [20] \\
\hline \multirow[t]{4}{*}{ Enrofloxacin } & 7.91 & 6.09 & & UV spectrophotometry & {$[21]$} \\
\hline & 7.74 & 5.88 & & CE & [22] \\
\hline & 7.91 & 6.09 & & UV spectrophotometry & [22] \\
\hline & 7.90 & 6.22 & -0.19 & 1H-NMR titration & [14] \\
\hline \multirow[t]{3}{*}{ Moxifloxacin } & 9.29 & 6.25 & & Potentiometry / UV spectrophotometry & [23] \\
\hline & 9.1 & 6.8 & & Potentiometry / UV spectrophotometry / Fluorimetry & [24] \\
\hline & 9.53 & 6.23 & & Potentiometry & [25] \\
\hline \multirow[t]{5}{*}{ Ofloxacin } & 8.28 & 5.97 & & Potentiometry / Fluorimetry & [19] \\
\hline & 8.20 & 6.20 & 5.20 & $\mathrm{CE}$ & [15] \\
\hline & 8.28 & 6.10 & & Potentiometry & [20] \\
\hline & 7.18 & & & UV spectrophotometry & [20] \\
\hline & & 6.13 & -0.43 & 1H-NMR titration & [14] \\
\hline
\end{tabular}


Table III. Precision and accuracy parameters of FQs separation in BGE 100 mM phosphoric acid

\begin{tabular}{lcccc}
\hline Substance & $\begin{array}{c}\text { Migration time (min) } \\
\text { RSD (\%) migration time }\end{array}$ & $\begin{array}{c}\text { Peak area } \\
\text { RSD (\%) Peak area }\end{array}$ & $\begin{array}{c}\text { Electrophoretic mobility } \\
(\mathrm{cm} / \mathrm{kV} \text { min) }\end{array}$ \\
\hline ENO & 6.60 & 0.05 & 10.13 & 0.02 \\
CIP & 6.77 & 0.05 & 12.10 & 32.85 \\
OFL & 6.88 & 0.06 & 14.18 & 32.04 \\
ENR & 7.07 & 0.06 & 13.11 & 0.03 \\
SAR & 7.18 & 0.06 & 15.05 & 0.05 \\
MOX & 7.32 & 0.06 & 10.96 & 31.54 \\
\hline
\end{tabular}

Table IV. Linearity regression data in BGE $100 \mathrm{mM}$ phosphoric acid (concentration range: $100-350 \mu \mathrm{g} / \mathrm{ml}$ ) and detection and quantification limits for the FQs separation

\begin{tabular}{lccc}
\hline Substance & Regression equation & Correlation coefficient & LOD $(\mu \mathrm{g} / \mathrm{ml})$ \\
\hline ENO & $\mathrm{y}=0.5048 \mathrm{x}-0.1133$ & 0.9913 & 19.87 \\
CIP & $\mathrm{y}=0.4303 \mathrm{x}+7.4524$ & 0.9916 & 16.66 \\
OFL & $\mathrm{y}=0.3415 \mathrm{x}-8.5305$ & 0.9948 & 10.41 \\
ENR & $\mathrm{y}=0.7859 \mathrm{x}-27.474$ & 0.9912 & 35.54 \\
SAR & $\mathrm{y}=0.3809 \mathrm{x}-6.9057$ & 0.9980 & 34.72 \\
MOX & $\mathrm{y}=0.5525 \mathrm{x}+0.901$ & 0.9927 & 19 \\
\hline
\end{tabular}

$$
\mathrm{pH}=\mathrm{p} K_{\mathrm{a}}+\log ([\mathrm{A}-] /[\mathrm{HA}])
$$

The connection between macroconstants, $\mathrm{pH}$ and the electrophoretic mobility is evident $[12,15,22]$. Previously, in the Results section we proved that the low values of $\mathrm{pH}$ lead to lower migration times and to a better resolution of separation (Figure 4). This can be explained on the basis of behavior in acidic media of FQs and the close relations which exist between macroconstants, $\mathrm{pH}$ and the electrophoretic mobility. The addition of organic solvents did not influence positively the resolution of the separation, because of the alteration of polarity and viscosity of BGE. Both the electroosmotic and electrophoretic velocities are directly proportional to the field strength, so the use of the highest voltages possible will result in the shortest times for the separation, the limiting factor being the capacity of the electrophoretic system to dissipate the heat generated by the Joule effect. The electrophoretic mobility and the EOF are influenced strongly by viscosity and consequently temperature $[27,28]$.

The proposed separation method was evaluated on the basis of validation parameters: precision (migration time and peak area), linearity, limit of detection (LOD) and limit of quantification. Very similar migration times and peak areas were obtained for six repeated measurements of the six compounds; the RSD values were smaller than $0.1 \%$ indicating a good precision of the method (Table III).

The individual linear regression equations for each FQ were calculated on a specific concentration range according to six concentration and three replicates per concentration. All correlation coefficients were over 0.99 , which demonstrates a very good linearity of the method. The limit of detection (LOD) was determined as the sample concentration that produces a peak with a height three times the level of the baseline noise, and the limit of quantification (LOQ) was calculated that produced a peak with 10 times the signal-to-noise ratio (Table IV) [29-32]. Data was statistic processed using GraphPad InStat v3.08 and Microsoft Excel programs.

On the base of the previous results we can affirm that CZE method with acidic BGE can be used for identification, quantitative determination and separation of different FQs chemical structure.

\section{Conclusions}

In CZE separation the resolving power is based on the difference in electric charge relative to molecular size of the analytes. The electric charge depends on the number of alkaline and acidic groups of the analyte, but also on the $\mathrm{pH}$ of the electrolyte because dissociation of these groups is $\mathrm{pH}$ dependent. The class of FQs presents numerous structural similarities, which lead to similar electrophoretic behavior (very close migration times and electrophoretic mobilities), their simultaneous separation from complex mixture representing a real challenge. CZE using an acidic BGE has proven to be a fast and efficient separation tool not for just the separation of FQs from different generations having different structural characteristics but also for the separation of FQs from the same generation. The analytical conditions were optimized; each analytical parameter role was verified, in order to achieve the separation. The validation parameters of the methods were then evaluated: precision (RSD for migration time and peak area), linearity as well as limit of detection (LOD) and limit of quantification (LOQ) for each compounds was calculated. Our validated method is therefore general and reliable, with the potential to separate FQs in environmental, food and biological samples. Also, this separation can be achieved in purely aqueous BGE which is also environmental friendly. 


\section{Acknowledgement}

The authors are grateful to Bayer Schering Pharma AG for providing the moxifloxacin hydrochloride.

\section{References}

1. Beale JM jr. Synthetic antibacterial agents, in Block JH, Beale JM (eds): Wilson and Gisvold's Textbook of Organic Medicinal and Pharmaceutical Chemistry 11th edition. Lippincott Williams \& Wilkins. Philadelphia, 2004, 247-258.

2. Andersson MI, MacGowan AO. Development of the quinolones. J Antimicrob Chemother. 2003;51:1-11.

3. Bolon MK. The newer fluoroquinolone. Med Clin N Am. 2011;95:793-811.

4. Jimidar Ml. Theoretical considerations in performance of various modes of CE, in Ahuja S, Jimidar M (eds): Capillary Electrophoresis Methods for Pharmaceutical Analysis, Volume 9 (Separation Science and Technology) 1 edition. Academic Press Elsevier, Amsterdam, 2008, 9-42.

5. Pérez-Ruiz T, Martínez-Lozano C, Sanz A, Bravo E. Separation and simultaneous determination of quinolone antibiotics by capillary zone electrophoresis. Chromatographia. 1999;49:419-423.

6. Sun H, He P, LV Y, Liang S. Effective separation and simultaneous determination of seven fluoroquinolones by capillary electrophoresis with diode-array detector. J Chromatogr B. 2007;852:145-151.

7. Ferdig M, Kaleta A, Thanh Vo TD, Buchberger W. Improved capillary electrophoretic separation of nine (fluoro)quinolones with fluorescence detection for biological and environmental samples. Journal of Chromatography A. 2004;1047:305-311.

8. Yang Z, Qin W. Separation of fluoroquinolones in acidic buffer by capillary electrophoresis with contactless conductivity detection. J Chromatogr A. 2009;1216:5327-5332.

9. Faria AF, de Souza MVN, de Almeida MV, de Oliveira MAL. Simoultaneous separation of five fluoroquinolone antibiotics by capillary zone electrophoresis. Anal Chim Acta. 2006;579:185-192.

10. Sun J, Sakai S, Tauchi Y, et al. Determination of lipophilicity of two quinolone antibacterials, ciprofloxacin and grepafloxacin, in the protonation equilibrium. Eur J Pharm Biopharm. 2002;54:51-58.

11. Lemaire S, Tulkens PM, Van Bambeke F. Contrasting effects of acidic pH on the extracellular and intracellular activities of the anti-gram-positive fluoroquinolones moxifloxacin and delafloxacin against Staphylococcus aureus. Antimicrob Agents Ch. 2011;55:649-658.

12. Noszál B. Acid-base properties of bioligands, in K. Burger (eds): Biocoordination chemistry: coordination equilibra in biologically active system. Ellis Horwood, Chichester UK, 1990, 18-41.

13. Lee DS, Hun HJ, Kim K, et al. Dissociation and complexation of fluoroquinolone analogues. J Pharm Biomed Anal. 1994;12:157-164.

14. Rusu A, Tóth G, Szőcs L, et al. Triprotic site-specific acid-base equilibria and related properties of fluoroquinolone antibacterials. J Pharm Biomed Anal. 2012;66:50-57.

15. Lin CE, Deng YJ, Liao WS, et al. Electrophoretic behavior and pKa determination of quinolones with a piperazinyl substituent by capillary zone electrophoresis. J Chromatogr A. 2004;1051:283-290.
16. Lombardo-Agüí M, García-Campana AM, Gámiz-Gracia L, Cruces Blanco C. Laser induced fluorescence coupled to capillary electrophoresis for the determination of fluoroquinolones in foods of animal origin using molecularly imprinted polymers. J Chromatogr A. 2010;1217: 2237-2242.

17. Yang Z, Qin W. Separation of fluoroquinolones in acidic buffer by capillary electrophoresis with contactless conductivity detection. J Chromatogr A. 2009; 1216:5327-5332.

18. European Pharmacopoeia 7th edition. Council of Europe, Strasbourg, 2010, 367.

19. Drakopoulos Al, loannou PC. Spectrofluorimetric study of the acid-base equilibria and complexation behavior of the fluoroquinolone antibiotics ofloxacin, norfloxacin, ciprofloxacin and pefloxacin in aqueous solution. Anal Chim Acta. 1997;354:197-204.

20. Park HR, Kim TH, Bark KM. Physicochemical properties of quinolone antibiotics in various environments. Eur J Med Chem. 2002;37:443-460.

21. Barbosa J, Barrón D, Jiménez-Lozano E, Sanz-Nebot V. Comparison between capillary electrophoresis, liquid chromatography, potentiometric and spectrophotometric techniques for evaluation of pKa values of zwitterionic drugs in acetonitrile-water mixtures. Anal Chim Acta. 2001;437:309-321.

22. Jiménez-Lozano E, Marqués I, Barrón D, Beltrán JL, Barbosa J. Determination of pKa values of quinolones from mobility and spectroscopic data obtained by CE and a DAD. Anal Chim Acta. 2002;464:37-45.

23. Langlois MH, Montagut M, Dubost JP, Grellet J, Saux MC. Protonation equilibrium and lipophilicity of moxifloxacin. J Pharm Biomed Anal. 2005;37:389-393.

24. Lorenzo F, Navaratnam S, Edge R, Allen NS. Primary Photophysical Properties of Moxifloxacin - A Fluoroquinolone Antibiotic. Photochem Photobiol. 2008;84:1118-1125.

25. Neves P, Leite A, Rangel M, de Castro B, Gameiro P. Influence of structural factors on the enhanced activity of moxifloxacin: a fluorescence and EPR spectroscopic study, Anal Bioanal Chem. 2007;387:1543-1552.

26. Takács-Novák K, Noszál B, Hermecz I, et al. Protonation equilibria of quinolone antibacterials. J Pharm Sci. 1990;79:1023-1028.

27. Altria KD. Introduction to CE and the Use of CE in Pharmaceutycal Analysis, in Altria KD (eds): Analysis of Pharmaceuticals by Capillary Electrophoresis. Chromatographia CE-Series, Vieweg, 1998, 1-18.

28. Sänger-van de Griend CE. General Considerations to Improve Performance of CE Methods, in Ahuja S, Jimidar M (eds): Capillary Electrophoresis Methods for Pharmaceutical Analysis. Elsevier/Academic Press, Amsterdam, 2008, 123-144.

29. ICH. Validation of analytical procedures: text and methodology Q2(R1). Geneva, 2005

30. Peters FT, Drummer OH, Musshoff F. Validation of new methods. Forensic Sci Int. 2007;165:216-224.

31. Peters FT, Maurer $\mathrm{HH}$. Bioanalytical method validation and its implications for forensic and clinical toxicology - A review, in De Bièvre P, Günzler $\mathrm{H}$ (eds.): Validation in Chemical Measurement, Springer-Verlag, Berlin Heidelberg, 2005, 1-9.

32. Ross GA. Instrumental validation in capillary electrophoresis and checkpoints for method validation, in De Bièvre P, Günzler $H$ (eds.): Validation in Chemical Measurement, Springer-Verlag, Berlin Heidelberg, 2005, 14-23. 